\title{
Developing new approaches for detecting and preventing Aedes aegypti population outbreaks: basis for surveillance, alert and control system
}

\author{
Lêda Regis/ ${ }^{+}$, Antonio Miguel Monteiro', Maria Alice Varjal de Melo-Santos, \\ José Constantino Silveira Jr², André Freire Furtado, Ridelane Veiga Acioli ${ }^{3}$, Gleice Maria Santos, \\ Mitsue Nakazawa, Marilia Sá Carvalhơ ${ }^{4}$, Paulo Justiniano Ribeiro Jr5 , Wayner Vieira de Souza²
}

Departamento de Entomologia ${ }^{2}$ Departamento de Saúde Coletiva, Centro de Pesquisas Aggeu Magalhães-Fiocruz, Av. Prof. Moraes Rego s/n, 50670-420 Recife, PE, Brasil 'Instituto Nacional de Pesquisas Espaciais-INPE, São José dos Campos, SP, Brasil ${ }^{3}$ Secretaria Municipal de Saúde, Recife, PE, Brasil ${ }^{4}$ Escola Nacional de Saúde Pública Sérgio Arouca-Fiocruz, Rio de Janeiro, RJ, Brasil ${ }^{5}$ Departamento de Estatística, Universidade Federal do Paraná-UFPR, Curitiba, PR, Brasil

A new approach to dengue vector surveillance based on permanent egg-collection using a modified ovitrap and Bacillus thuringiensis israelensis (Bti) was evaluated in different urban landscapes in Recife, Northeast Brazil. From April 2004 to April 2005, 13 egg-collection cycles of four weeks were carried out. Geo-referenced ovitraps containing grass infusion, Bti and three paddles were placed at fixed sampling stations distributed over five selected sites. Continuous egg-collections yielded more than four million eggs laid into 464 sentinel-ovitraps over one year. The overall positive ovitrap index was $98.5 \%$ (over 5,616 trap observations). The egg density index ranged from 100 to 2,500 eggs per trap-cycle, indicating a wide spread and high density of Aedes aegypti (Diptera: Culicidae) breeding populations in all sites. Fluctuations in population density over time were observed, particularly a marked increase from January on, or later, according to site. Massive egg-collection carried out at one of the sites prevented such a population outbreak. At intra-site level, egg counts made it possible to identify spots where the vector population is consistently concentrated over the time, pinpointing areas that should be considered high priority for control activities. The results indicate that these could be promising strategies for detecting and preventing Ae. aegypti population outbreaks.

Key words: dengue vector - population densities - ovitraps - Bti - vector control - Recife

Dengue fever is currently the most globally widespread insect-born virus infection, causing 50 - 100 million cases per year in more than 100 endemic countries. Dengue virus (DENV) is transmitted to humans mainly by Aedes aegypti Linnaeus and Aedes albopictus Skuse (Diptera: Culicidae) mosquitoes, which are also vectors of yellow fever, West Nile and other viruses.

The high efficiency of the virus transmission mechanism combined with a number of biological features of $A e$ aegypti, its main vector, contribute to explosive epidemics of dengue, which are mainly contained by the immunity status of the human population. Like other vector mosquitoes, the Ae. aegypti population is subject to continual fluctuations in density, increasing rapidly in size due to high fecundity and fertility and short generation time. However, some behavioural features make this species a more efficient pathogen vector and more difficult to control than other species of mosquito. For instance, the female Aedes' multiple blood meals increase

Financial support: MS-Decit/CNPq(50154020332); CNPq(301277/2005); Fiocruz-PDTSP/Rede Dengue (RDVE-03)

+ Correspondig author: leda@cpqam.fiocruz.br

Received 3 August 2007

Accepted 11 February 2008 the opportunities for virus inoculation (Scott et al. 2000). Larval behavior make it very difficult to monitor them at breeding sites by taking water samples. Culex quinquefasciatus (Say) lay grouped eggs and use a pheromone to aggregate oviposition by co-specific females in well-defined large sites, favouring intervention for larval control. However, Aedes lay eggs in an enormous variety of containers, posing a real challenge for control of this species using larvicides alone, as is feasible in the case of Culex (Regis et al. 2000). Furthermore, the resistance of eggs to dry conditions greatly facilitate vector dispersion and capacity to remain in the environment.

As a vaccine is not yet available, preventing sudden increases in vector population is the only way of avoiding dengue transmission outbreaks. In a context where no important changes in human population immunity occur, an increase in the vector population and consequently in vector-to-human contact, will increase dengue virus transmission. It is known that changes in density are important in disease epidemiology because the vectorto-host ratio is a determinant of the vector capacity of a population (Black \& Moore 1996). The implementation of preventive measures targeting critical locations at specific times requires efficient vector surveillance tools and methods sensitive enough to predict or detect in real time a sudden mosquito population growth. Dengue vector surveillance is classically based on the Premise Index (PI) and the Breteau Index, both of which use visual detection of larvae in domestic containers. Ae. aegypti lar- 
vae visualization is for many reasons an inaccurate technique, especially because of the larvae's ability to escape rapidly and their capacity to remain submerged for long periods (Clements 1992). The percentage of premises or containers where Aedes larvae are found, registering as positive a container whether just one or thousands larvae are present does not provide information regarding mosquito population density, and these indices do not therefore seem to be an adequate way of meeting vector surveillance needs.

Given the biological specificities of Aedes populations, trapping eggs or adult mosquitoes would be a more appropriate way of locating sites and times where action should be concentrated to prevent or lessen the intensity of disease outbreaks. Using mosquito egg traps for vector surveillance seems to be a current trend in dengue endemic countries, since this method allows better assessment of infestation densities than the conventionally used methods based on the search for larvae (Ai-leen \& Song 2000, Braga et al. 2000, Polson et al. 2002, Morato et al. 2005).

The fact that high-cost and long-term programs to control dengue vector population very often do not meet with success suggests that preventing and controlling the disease will require new vector surveillance and control technologies based on field studies of population biology and spatial-temporal distribution of the vector in its natural environment.

We present here a first report on the efforts of a network of research and public health institutions which have come together to offer a new insight and to develop new tools for mosquito population surveillance and control through the integration of environmental aspects, detection of risk factors and warning methods based on a longitudinal fieldstudy using a Geographical Database and Spatial Information Technology. The main purpose is to produce tools to provide more efficient outbreak detection and to prevent vector population outbreaks in space and time.

\section{MATERIALS AND METHODS}

Study sites - Recife City ( $8^{\circ} 03^{\prime} \mathrm{S}, 34^{\circ} 52^{\prime} \mathrm{W}$, mean elevation: $5 \mathrm{~m}$ ) is the main lymphatic filariasis (LF) endemic area and the second for dengue cases in Brazil. With 1.4 million inhabitants living in a $209 \mathrm{Km}^{2}$ area, with many rivers and canals, poor sanitation conditions, high temperatures (ranging from $22^{\circ} \mathrm{C}$ to $32^{\circ} \mathrm{C}$ ) and relative air humidity $(70 \%-90 \%)$ throughout the year, the city has excellent conditions for breeding mosquitoes all year round, which explains the maintenance of LF and dengue transmission by $C x$. quinquefasciatus and $A e$. aegypti respectively. A hot season with sparse rainfall from January-April is followed by a heavy rainy season (May-August) and a dry season (September-December). In recent years, the local health service has established a structured mosquito surveillance and control program. The Environmental Health Program currently employs 726 agents (ASA) visiting premises every two months. Among other health actions, they are responsible for the control of LF and dengue vectors, using Bacillus sphaericus and Baccilus thuringiensis israelensis (Bti) as larvicides in the whole urban area, as well as for environmental management, information, education and mobilization.
Five sites encompassing seven of the 94 districts of Recife were selected for this study (Fig. 1), based on the disease transmission risk (DTR- high, medium and low risk scores) and life quality (LQ-scores I to III) stratifications, both of which are drawn up by the Recife City Municipality, and the selection of districts representing the different landscapes found in the city.

Site 1 - Districts: Casa Forte and Parnamirim - with a surface area of $1.17 \mathrm{~km}^{2}$ and a population density of 21,386 inhabitants $/ \mathrm{km}^{2}$ living predominantly in high-rise buildings with up to 20-40 floors. This site is classified as having low DTR and high LQ (score I).

Site 2 - District: Brasília Teimosa, located on the sea front with a $0.62 \mathrm{~km}^{2}$ surface area, population density of 30,895 inhabitants $/ \mathrm{km}^{2}$ living in very small dwellings. The site is classified as having high DTR and low LQ (score III).

Site 3 - District: Engenho do Meio - with $0.89 \mathrm{~km}^{2}$ area, a density of 11,865 inhabitants $/ \mathrm{km}^{2}$ living predominantly in low-rise individual houses, more often with structured urbanization, though incorporating small slums. This site is heterogeneous having low to medium DTR and LQ scores I and III.

Site 4 - Districts: Morro da Conceição and Alto José do Pinho - Taken as a whole the area represents $0.79 \mathrm{~km}^{2}$. Each district is located on a small hill (50 and $62 \mathrm{~m} \mathrm{high),}$ the highest ground in Recife. The inhabitants $(10,560 /$ $\mathrm{km}^{2}$ ) live, for the most part, in unplanned housing. This site is classified as medium DTR and has LQ scores of II and III.

Site 5 - Dois Irmãos and Sítio dos Pintos Districts, suburban areas located near to a remnant of the Atlantic Forest. Households are usually spaced out and flanked by green areas. This site has $1.16 \mathrm{~km}^{2}$ area and the lowest demographic density: 3,737 people/ $\mathrm{km}^{2}$, with high DTR and low LQ (score III).

The Design of the Experiment and its Spatial Epidemiological Database - The experiment started in February 2004, with full involvement of the local health service through ASA. It is based on an urban socio-environmental stratification of Recife into five sites. At each site, 80 to 100 ovitraps have been installed, geo-referenced and registered in the Recife-SAUDAVEL Geographic Epidemiological Database (GED). The ASA have also collected information on environmental conditions such as the presence of outdoor yards, the water supply system, and water storage habits in the premises hosting the traps. Continuous egg collection was carried out using 464 sentinel-ovitraps (S-OVT) placing 80-100 traps per site. Each S-OVT was installed at a fixed sampling station, where it remained for 24 months (data from the first year of egg-counting are reported in this article, while those from the second year are being analyzed for publication). The eggs were counted on a rota basis, i.e., 1/4 of the traps each week. These data are inserted into the database using a web-based interface that has been developed by the SAUDAVEL network (Monteiro et al. 2005) at the National Institute for Spatial Research-INPE and at $\mathrm{CPqAM} /$ Fiocruz. This has been designed to be a webbased entry to the SAUDAVEL database. It should avoid 


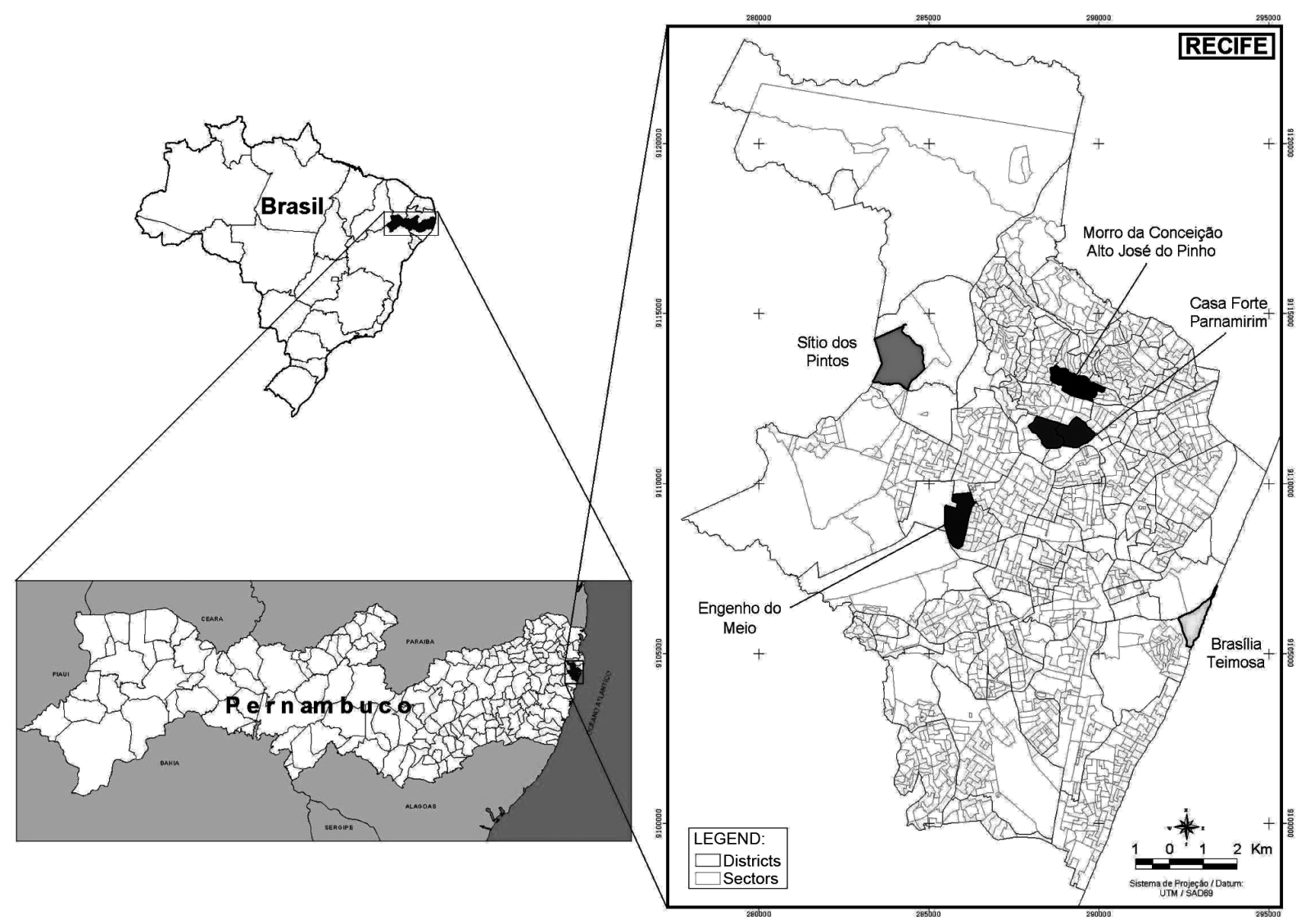

Fig. 1: the location of the study sites in Recife, Brazil.

complex analysis and provides an easy way of browsing the geographical database and having quick summaries for some spatio-temporal queries in the stored data. Remote sensing satellite imagery, pictures of the traps, meteorological data and census tract data are integrated through the SAUDAVEL-GED. Climatic data, temperature, relative humidity, and rainfall are daily recorded at a point-station in Recife monitored by the National Institute of Meteorology. An intensive control strategy has been introduced to integrate and reinforce the basic measure (larvicide with a Bti product) applied as part of the government program for controlling the Aedes population. It is based on mass collection of Aedes eggs using a large number of ovitraps. This control intervention was implemented from December 2004 to May 2005 at the Sites 1 and 3.

Geo-referenced S-OVT - A modified model of the conventional ovitrap (Fay \& Eliason 1966) was used for sampling Aedes eggs. It consists of a black plastic cup initially filled with $1 \mathrm{I}$ of grass infusion diluted in water to $30 \%$. However, due to water evaporation a number of traps were found empty after four weeks at the samplingstation, thus the cups were replaced by larger containers with $2 \mathrm{I}$ of infusion. Three $5 \times 15 \mathrm{~cm}$ wooden paddles are vertically fixed with clips to the inner wall of the cup as oviposition substrates. A commercial Bti-based product ( $2 \mathrm{~g} /$ trap) was added as a larvicide, allowing it to remain in the field without risk of becoming a larval habitat. This trap design was based on a previous field evaluation of ovitraps containing grass infusion and Bti (Santos et al. 2003), which results have shown that: 1- Bti does not reduce the attractiveness of the trap for oviposition by gravid females; 2- the presence of this larvicide removes the risk of transforming the ovitrap into a mosquito development site; and 3- more eggs were laid in the Bti treated trap compared to the control. We have recently shown that the larvicidal activity of Bti can persist for six months in containers protected from direct sunlight (Araujo et al. 2007), corroborating similar results on Bti long residual effects reported by others authors (Mulla et al. 2004, Benjamin et al. 2005, Setha et al. 2007). Besides being an efficient and safe larvicide (Regis et al. 2001), Bti seems to work as an oviposition stimulant for Ae. aegypti and Ae. albopictus (Santos et al. 2003, Stoops 2005).

Paddles, Bti and infusion were replaced monthly. The trap was hung in the exterior area of a residential premise $1 \mathrm{~m}$ above ground level in the shade and protected from rainfall. Each trap site was geo-referenced, photographed, and its surroundings described, focusing on water supply frequency, water storage containers and other aspects favoring mosquito breeding. The data have been registered in the SAUDAVEL-GED. After being air-dried at room temperature, labelled paddles were examined under stereoscopic microscope and the number of eggs was recoded with the aid of a manual cell counter.

Control ovitraps (C-OVT) - For the purposes of mass collection of eggs, a higher Bti dosage (4g/trap) was used 
in 21 of $10 \%$ infusion per C-OVT. The aim was to set two traps per premises and up to six per "strategic place". A total of 5,602 C-OVT have been installed, 3,685 of them placed within site $3\left(4,140\right.$ traps $\left./ \mathrm{km}^{2}\right)$, and 1,917 at site 1 $\left(1,638\right.$ traps $\left./ \mathrm{km}^{2}\right)$. The paddles were taken to the Health Service every two months, incinerated in an appropriate manner and replaced with new ones. The Bti and infusion were also replaced. The overall number of eggs collected in these traps was estimated on the basis of the average number of eggs per S-OVT simultaneously colleted from the corresponding site.

Sentinel sampling-stations distribution - Spatial units were defined using a grid of cells measuring 40 x $40 \mathrm{~m}$ at each site. $20 \%$ of the units, as well as one premise within each cell were randomly chosen to set the ovitraps (Fig. 2 ). The number of ovitraps installed at the different sites was as follows: site 1: 100; site 2: 80 ; site 3: 100 ; site 4: 100; site 5: 84 . Due to operational difficulties the number of ovitraps at sites 1 and 5 was lower than initially planned. Sentinel-ovitrap distribution varied from 63 to $129 \mathrm{traps} / \mathrm{km}^{2}$ at different sites. Through this sampling plan, an overall percentage of $2.9 \%$ of the houses within the sites have been sampled.

Aedes species identification - Fourth instar larvae (L4) reared in the laboratory from field-collected eggs were used for species identification. Eggs collected in 2025 S-OVT per site during one week in April 2004 were

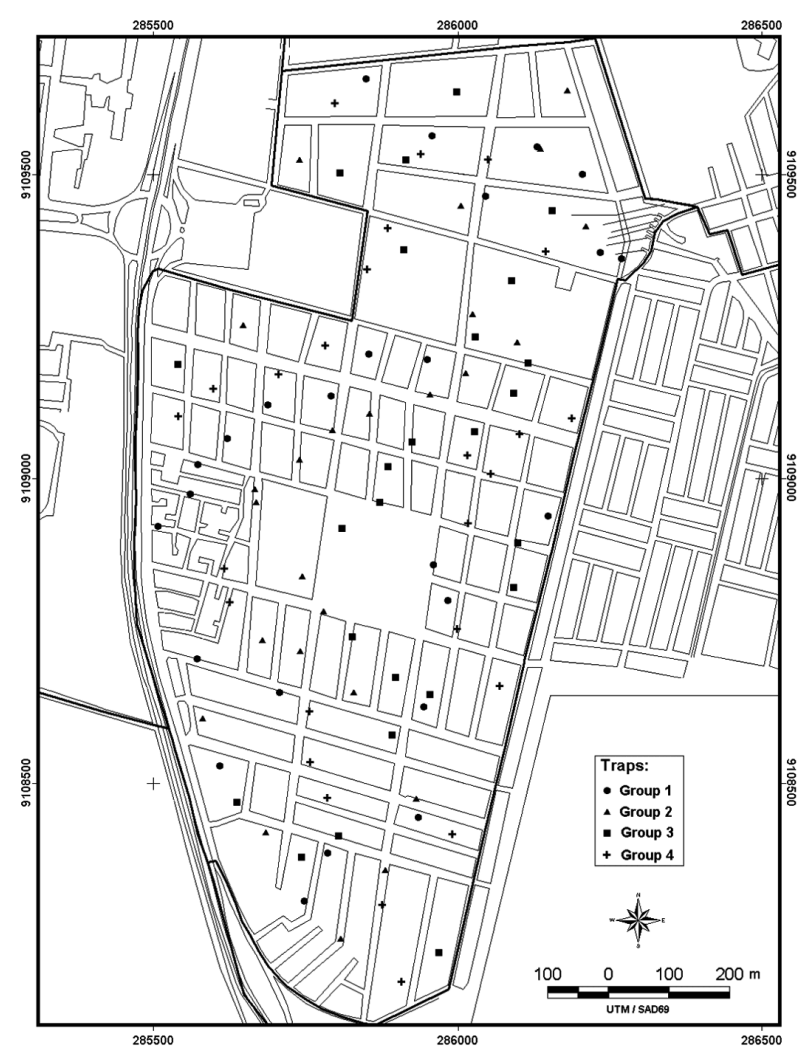

Fig. 2: the geographical distribution of 100 sentinel ovitraps placed within the site 3 in Recife, Brazil. The eggs collected during a 28-day cycle in each group of 25 traps were counted weekly. used. For sample size calculation Ae. albopictus prevalence of at least $0.1 \%$ was assumed, based on a recent survey carried out in different districts of the city (data not shown). Assuming a hypergeometric distribution with $p=1 / 1000$, the sample size required per district was set as 1,000 identified individuals.

Statistical analysis - Using the digital geographical database, spatial distribution of the intra-site critical areas for egg counts were analysed, using open source software (TerraView - www.dpi.inpe.br/terraview), by calculating the Kernel density estimator (Bailey \& Gatrell 1995). The spatial statistical analysis capacity built into the TerraView package has been much improved by the SAUDAVEL experiment Aedes spp. density monitoring alert system and its multi-institutional network of support. To analyse the predictive power of a specific egg count we calculated the Pearson's correlation coefficients with respective scatters plots correlating mean number of eggs in a given count compared with the number of eggs counted in the previous week.

Ethical approval - The study project was reviewed and approved by the Research Ethics Committee of the Centro de Pesquisas Aggeu Magalhães-Fiocruz, Brazil.

\section{RESULTS}

The performance of the ovitrap - Over the study period, relatively few ( $<1 \%$ of 464$)$ S-OVTs needed to be replaced due to cup damage or disappearance. The use of three paddles per trap provided $225 \mathrm{~cm}^{2}$ of oviposition substrate. Results showed that such an area is enough to support a high egg deposition capacity. As for example, at 48 out of 5,616 events, a single trap caught $>4,000$ eggs over a 4-week cycle. The overall mean number of eggs per trap was $722.4 \pm 788.3$ with a maximum of 7,784 eggs laid in a single trap. The distribution of eggs per trap (Fig. 3) suggests that the maximum capacity could not be reached, so the number of eggs collected seems not to be limited by the trap's capacity.

Aedes species - A total of 8,897 L4 were identified to species. Ae. aegypti and Ae. albopictus were found at all the sites and no other Aedes species was recorded in this study. Ae. aegypti was the predominant species in 4 out of 5 sites, accounting for $99.9 \%$ (site 2, located $11.6 \mathrm{~km}$ from the forest), 99.4\% (site 3), 94.0\% (site 4) and $87.1 \%$ (site 1). Ae. albopictus was the predominant

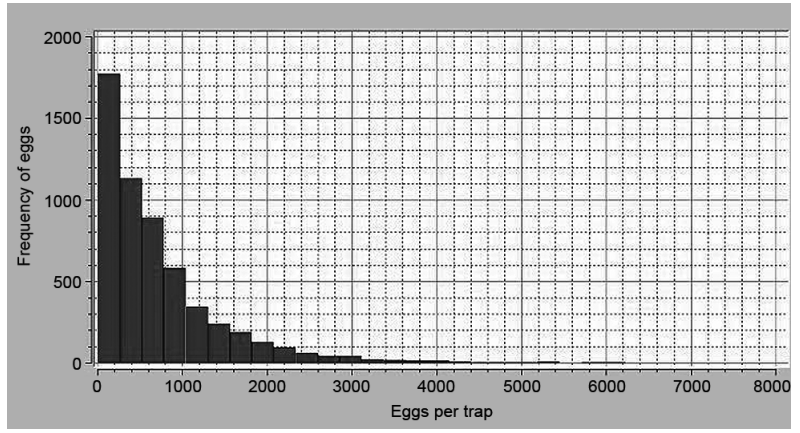

Fig. 3: frequency of the number of eggs collected per sentinel ovitrap. 
species $(88.4 \%)$ at site 5 , adjacent to the forest. The presence of Ae. albopictus, however, was not detected by the larvae search method used by the local health service, either at sites 2 and 3 during 2004 or at site 5 from March to December that year (Table).

Abundance and distribution of eggs - During the period studied, 13 egg-collection cycles were completed, the first between 27 April and 18 May 2004 and the last between 29 March and 19 April 2005, yielding a total of $4,055,372$ eggs. Oviposition activity was recorded the year round. Very high percentages of positive S-OVT (containing at least one Aedes egg) were found: 5,530 positive traps out of 5,616 observations over one year, meaning an overall positive ovitrap index of $98.5 \%$, with little variation among sites: from $97.6 \%$ (site 4 ) to $99.0 \%$ (site 2 ).

The mean number of eggs caught per S-OVT in a $28-$ day cycle egg density index (EDI) over one year indicated high densities of Aedes spp. breeding populations everywhere (Fig. 4) with marked fluctuations in time, means ranging from 100 to 2,500 eggs per trap-cycle. The higher EDI values, ranging from 400 to 2,500 (mean 954.1 \pm 944.4) eggs/trap-cycle, were recorded at site 2 , followed by site 1 (Fig. 4), where EDI ranged from 300 to 1,700 (mean $849.1 \pm 937.5$ ) eggs/trap-cycle and the lowest EDI $(100-750)$ were found at site 5. The EDIs were generally higher from January to August, a period that includes the heavy rainy season (May-August), than from September to December. Infestation intensity as well as its temporal distribution pattern was similar for sites 1 (high LQ), 2 (low LQ) and 4 (low-medium LQ): lower oviposition during the dry season followed by an important population growth starting in January and peaking in March (sites 1 and 2) or later in July (site 4). This sharp increase in oviposition activity, concomitant with temperature elevation and sparse rainfall, was specially accentuated in site 2 where the EDI increased 4.4 folds (from 425 to 1,893 eggs/trap-cycle) within two months (Fig. 4). Such population outbreak was not observed at site 3 (Fig. 4). A different egg distribution pattern over time, with the lowest densities occurring from January to March, was observed in the less densely inhabited area (site 5), where Ae. albopictus was the predominant species.
Fig. 5 shows the scatter plots demonstrating high correlation levels between the mean number of eggs per ovitrap $(\mathrm{p}<0.01$ for all sites) counted in a given week and the value recorded in the previous week. Each different trap group constitutes independent random samples and provides sample data from the whole population density in each district in different weeks. Therefore, the results suggest an important temporal dependence in the distribution of the eggs and constitute an important starting point for the development of an alert system.

Concerning the intra-site distribution of eggs, Fig. 6 shows the spatial analysis of eggs collected at site 2, on three different occasions: in December/2004, when the lowest number of eggs occurred and at the two peaks of breeding population, June/July 2004 and March 2005. Infestation hotspots were detected at some sampling stations for the full duration of the study, regardless of the periods of lowest and highest oviposition activity. The map representing the accumulated density of eggs at the site over the year also confirms this fact. Similar phenomenon was observed in the other studied sites (data not shown).

Mass egg collection as a control strategy - For site 3 it was estimated, based on the mean number of eggs collected in the S-OVT, that approximately 6.3 million eggs were collected and incinerated from December 2004 to April 2005. Differently from the observations at other sites, Aedes population density remained below the mean level at site 3 throughout this period (Figs 4, 7). At site 1, however, where a lower C-OVT concentration was used, an important increase in oviposition activity during the intervention was not prevented (Fig. 4).

\section{DISCUSSION}

A new approach to dengue vector surveillance based on permanent egg-collection using a modified ovitrap and Bti was evaluated in different intra-urban landscapes. Results from the first year of collection indicate that this could be a promising strategy for detecting $A e$. aegypti population outbreaks. In addition to being a sensitive tool as an indicator of reproductively active Aedes populations, the ovitrap provides an indirect estimate of the feeding activity of the mosquito population (Hoeck

TABLE

The Premise Index for Aedes aegypti and Aedes albopictus in the studied sites during 2004, according to the Health Department of Recife Municipality, Brazil

\begin{tabular}{|c|c|c|c|c|c|c|c|c|c|c|c|c|c|}
\hline \multirow{3}{*}{ Site } & \multirow{3}{*}{ District } & \multicolumn{12}{|c|}{ Premise Index in 2004} \\
\hline & & \multicolumn{2}{|c|}{ Cycle 1} & \multicolumn{2}{|c|}{ Cycle 2} & \multicolumn{2}{|c|}{ Cycle 3} & \multicolumn{2}{|c|}{ Cycle 4} & \multicolumn{2}{|c|}{ Cycle 5} & \multicolumn{2}{|c|}{ Cycle 6} \\
\hline & & $a e g y^{a}$ & albop $^{b}$ & aegyi & albop & aegy & albop & aegy & albop & aegi & albop & aegy & albop \\
\hline \multirow[t]{2}{*}{1} & Casa Forte & 0 & 0 & 0 & 0 & 0 & 0 & 0 & 0 & 0 & 0 & 0 & 0 \\
\hline & Parnamirim & 2.9 & 0 & 2.8 & 0.4 & 2.4 & 0.9 & 2.8 & 0.5 & 3.3 & 0 & 3.3 & 0 \\
\hline 2 & Brasília Teimosa & 2.0 & 0 & 0.6 & 0 & 0.8 & 0 & 1.2 & 0 & 1.1 & 0 & 1.1 & 0 \\
\hline 3 & Engenho do Meio & 8.0 & 0 & 2.5 & 0 & 3.9 & 0 & 2.2 & 0 & 1.9 & 0 & 1.9 & 0 \\
\hline \multirow[t]{2}{*}{4} & Morro da Conceição & 2.3 & 0 & 0.7 & 0.1 & 0.4 & 0 & 0.2 & 0 & 0 & 0 & 0 & 0 \\
\hline & Alto José do Pinho & 0.4 & 0 & 0.5 & 0 & 0.2 & 0 & 0.5 & 0 & 0 & 0 & 0 & 0 \\
\hline \multirow[t]{2}{*}{5} & Dois Irmãos & 0.2 & 0.2 & 0 & 0 & 0 & 0 & 0 & 0 & 0 & 0 & 0 & 0 \\
\hline & Sítio dos Pintos & 0 & 0 & 0 & 0 & 0 & 0 & 0 & 0 & 0 & 0 & 0 & 0 \\
\hline
\end{tabular}

a: Aedes aegypti; b: Aedes albopictus. 


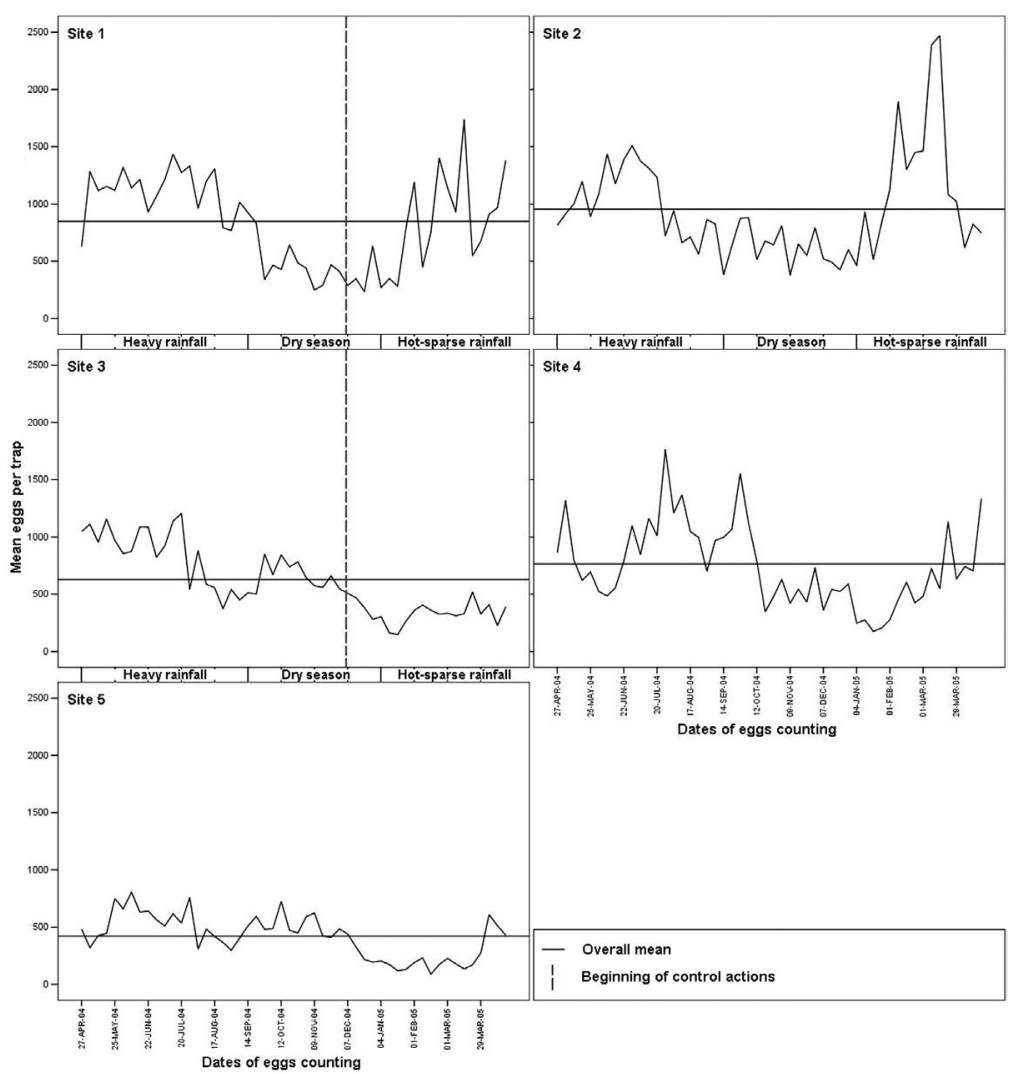

Fig. 4: weekly counts of eggs per ovitrap collected from 27 April 2004 to 19 April 2005 in the five different sites located in Recife, Brazil. The vertical line across sites 1 and 3 indicates the beginning of control intervention through massive eggs collection.

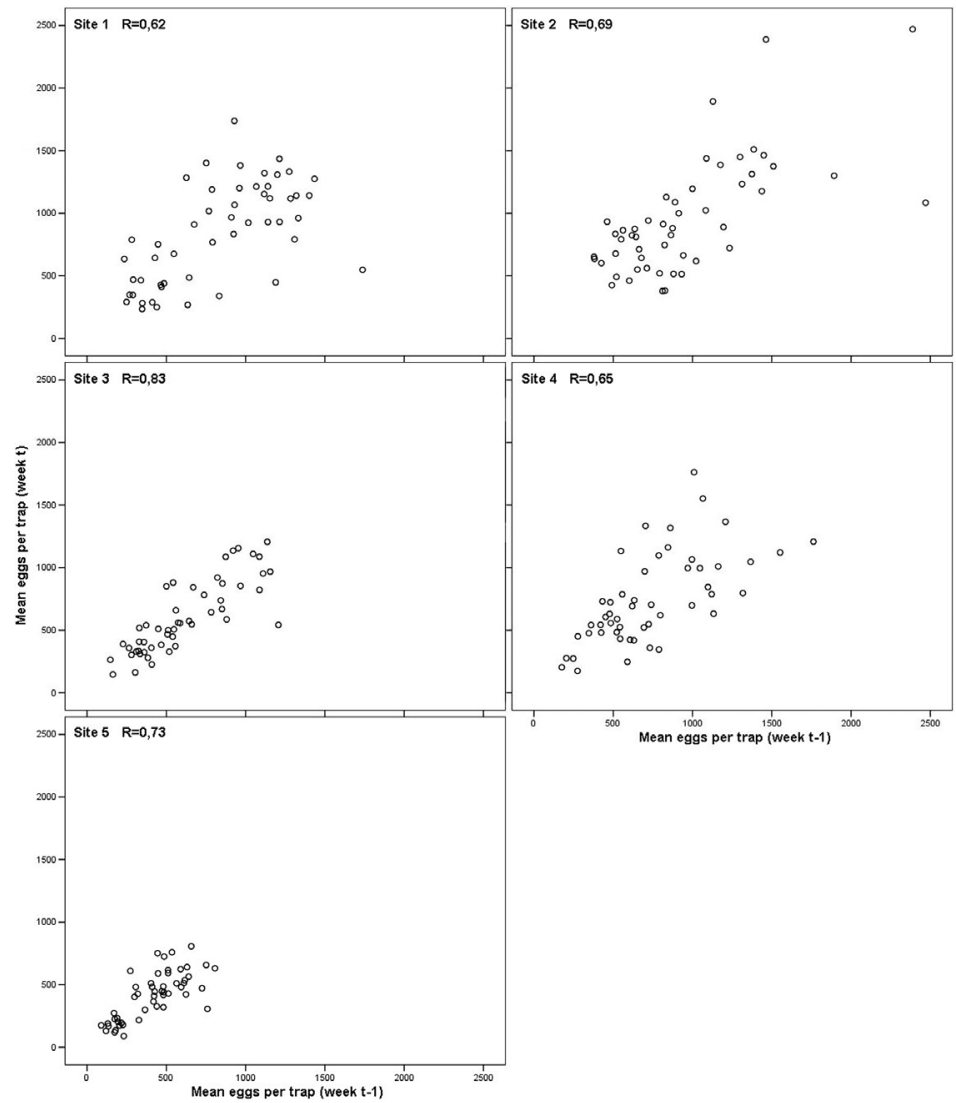

Fig. 5: scatter plots correlating the number of Aedes spp. eggs collected in a given week versus the previous week, for the five sites in Recife, Brazil. 


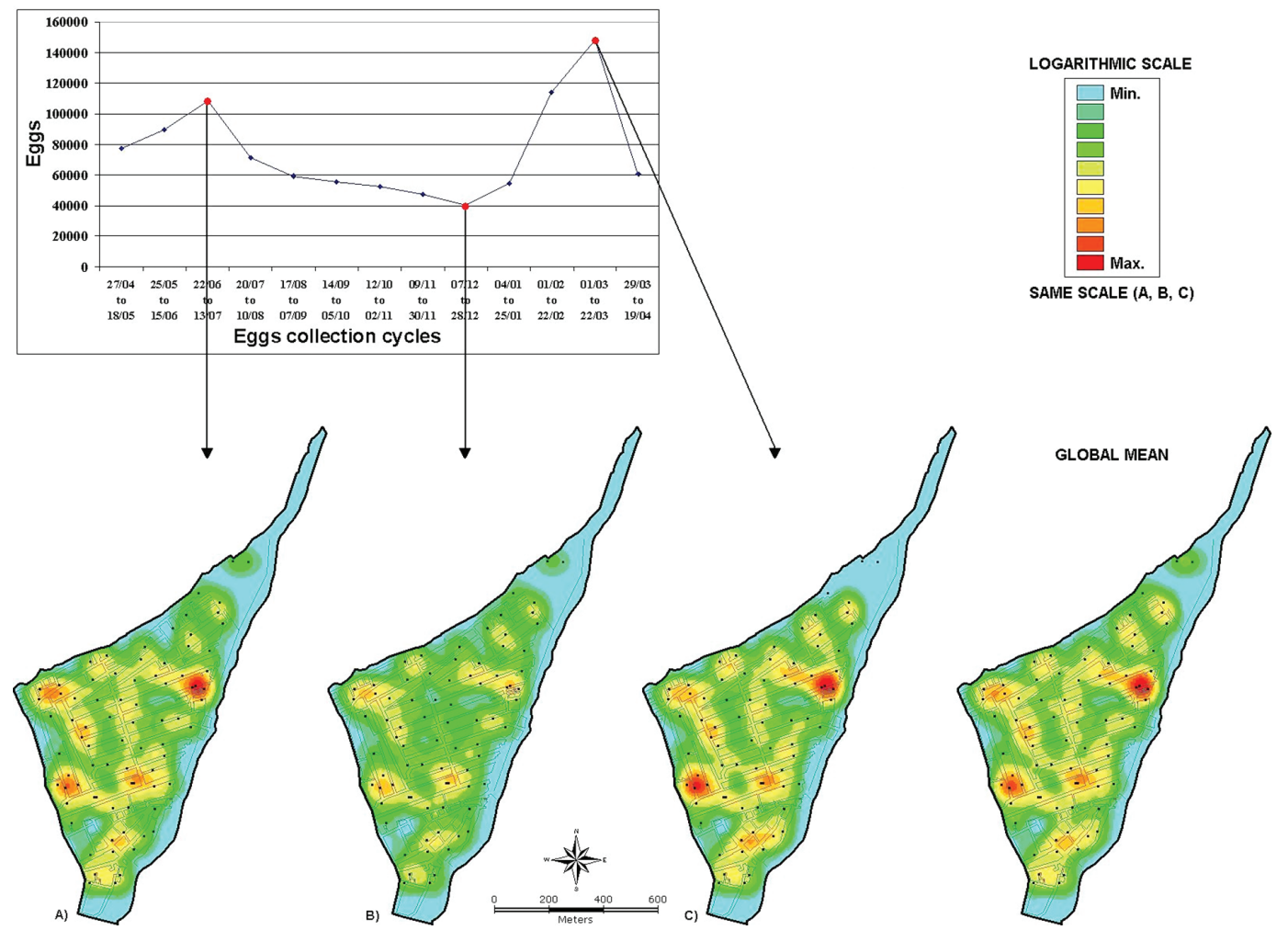

Fig. 6: Kernel density maps pointing critical areas for Aedes spp. eggs density within the site 2, on three selected occasions: June-July 2004 (A), December 2004 (B), and March 2005 (C). Map at the right side shows the global mean of eggs for the whole period (April 2004 to April 2005).

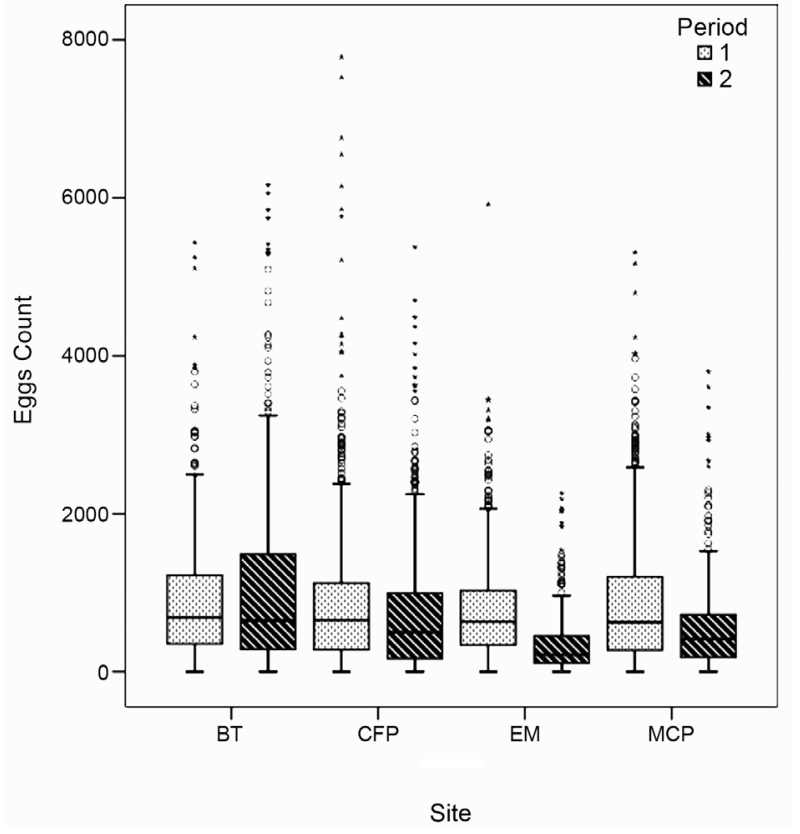

Fig. 7: comparison of eggs collected during the period 1 (April-November 2004) and the period 2 (December 2004 - April 2005) at sites 1 (CFP), 2 (BT), 3 (EM) and 4 (MCP). Eggs mass collections were carried out using 1,638 traps $/ \mathrm{km}^{2}$ in the site 1 (CFP) and 4,140 traps/ $\mathrm{km}^{2}$ in the site $3(\mathrm{EM})$ during the period 2. et al. 2003), and is also an extremely simple and easily adaptable device. The standard model (Fay \& Eliason 1966, WHO 1995) has been improved by the addition of hay infusion (Reiter et al. 1991) and since then the egg trap has been modified in various ways to fit local needs, usually increasing its efficiency. Some examples are the addition of a mesh to prevent the escape of adult mosquitoes (Ai-leen \& Song 2000) and a stick card to retain females (Ritchie et al. 2003). Furthermore, different types of egg substrates are used, such as wooden paddles of varying sizes (Swanson et al. 2000, Santos et al. 2003), seed germination cards used as a circular sheet or strips (Nasci et al. 2000, Polson et al. 2002, Hoeck et al. 2003, Barker et al. 2003) or cotton fabrics (Lenhart et al. 2005). Different types of containers with varying fluid capacities have also been used (Bellini et al. 1996, Swanson et al. 2000, Santos et al. 2003, Sant'Ana et al. 2006). The Municipality of Recife Health Department is currently using approximately 900 permanent ovitraps formed using disposable plastic bottles containing Bti as a larvicide, placed at strategic locations such as cemeteries, tyre storage areas and so forth.

This study has shown that the Bti-treated trap with an increased volume $(2 \mathrm{I})$ and oviposition substrate area $\left(225 \mathrm{~cm}^{2}\right)$ can safely remain in the field for up to two months showing an egg-collection capacity $(>7,000$ eggs/trap) capable of detecting not only slight but also large variations in the population size. 
Continuous egg-collection at fixed sampling stations yielded more than four million eggs over a 52-week period in 464 sentinel ovitraps distributed over five sites. No association between Aedes population densities and the socio-economic status of the inhabitants was found, since the second highest vector density was observed precisely where people have the highest life quality (site 1) and the lowest densities at a site with low life quality (site 5). Due to the oviposition behaviour of Aedes, which is a colonizer of any kind of water-holding container, this is not a surprising finding. A similar observation has also been reported in other Brazilian cities as Salvador (Teixiera et al. 2002b, Morato et al. 2005), Manaus (Ríos-Velasquez et al. 2007), and Rio de Janeiro (Maciel-de-Freitas et al. 2007). However, surprisingly, in Recife the PI for one of the districts (Casa Forte) in site1 was negative during 2004 (Table). The possible reasons for this discrepancy could be the inaccuracy of the visual method for detecting larvae used for PI, and the resistance of high-income households to allowing health workers to inspect their premises. On the other hand, a clear association between demographic concentration and Aedes density is revealed by our data: the site the most infested by Aedes was the most densely populated $\left(30,895\right.$ people $\left./ \mathrm{km}^{2}\right)$, while in the less infected area, human population density is eight times lower (3,737 people/ $\left.\mathrm{km}^{2}\right)$.

At the intra-site level, egg counts allowed spots to be identified where the vector breeding population is consistently concentrated over the time, pointing out areas within the grid that should be considered as high priority for stepping up control activities. This observation suggests the importance of the environmental conditions at household level as a determinant of mosquito breeding activity, and providing indirect evidence that adult Ae. aegypti do not move far from the place where they emerge. This agrees with the observations of Harrington et al. (2005), showing that Ae. aegypti tend to be spatially clustered at the household level in places where human hosts and oviposition sites are abundant. Therefore, the use of spatial analysis techniques, such as the Kernel density estimator, to identify hotspots of vector concentration based on ovitrap data can be very useful for guiding control action.

According to Black and Moore (1996), density shifts in mosquito populations can be a result of regular seasonal climatic changes in temperature, moisture, resources or the emergence of new broods of adults. In the case of dengue vectors a sudden density increase after rainfall could be due to the appearance of a large number of larvae as a consequence of a massive hatching of eggs accumulated on container walls during a dry period. The first rainfalls occurring in Recife after the dry season, when temperatures are rising could mark the onset Aedes population growth resulting in substantially high densities observed from January to August. Differences between sites concerning the time of year when the Aedes population starts to grow may be attributed to differences in the environment, especially the main type of containers available for oviposition and their location in or around the home. Quantitative differences in rainfall between sites are being investigated as another possible cause, us- ing pluviometers installed at each site. The association between climatic and other co-variables and the spatiotemporal distribution of Ae. aegypti population over a period of two years will be the subject of another article.

Although great efforts on the part of the government program to reduce the vector population through the systematic use of larvicides the epidemiological pattern of dengue cases in Brazil remains unchanged. According to Teixeira et al. (2002a, 2005) analysis of available data indicate limited effectiveness of vector control measures. Every year, the number of dengue cases increases considerably from January to June-July, decreasing steadily thereafter and remaining at a low endemic transmission level until December. Even when DENV-3 was introduced five years ago, in a context of total human susceptibility and well established Ae. aegypti populations everywhere, causing an explosive outbreak peaking in March, the seasonal pattern was maintained. This suggests that the vector density could be a strong determinant of dengue transmission intensity and also that vector abundance continues to be largely determined by seasonal climatic factors, indicating that efforts to control the vector are not showing apparent effects.

In Recife, where Bti has replaced temephos since the detection of Aedes population resistance to organophosphorous compounds in 2002, larvicidal cycles are regularly applied covering all 94 districts. However, the entomological data gathered during this study show high infestation levels in the sites studied and this may also be the case for the rest of the urban territory. For $r$-strategist species, like most mosquitoes, a very high proportion of individuals have to be killed to cause some impact on the target population (Schofield 1991). Due to the large number of site types colonized by Ae. aegypti in urban spaces it is very difficult to reach and treat most of them. The active participation of the community in control programs is essential to reduce the number of potential Ae. aegypti breeding sites. This has been demonstrated by a successful program based on biological control and collection of discarded containers by communal health workers in Vietnam (Kay \& Nam 2005), as well as by community involvement in Cuba (Spiegel et al. 2002, Toledo-Romani et al. 2006). Unfortunately, such wellstructured community involvement "is more difficult to establish and maintain in societies with a strong culture of individualism" (Hales \& Panhius 2005).

We hypothesized that directing control measures simultaneously against two mosquito phases could help to reduce Ae aegypti population. According to our results, stepping up control action by integrating egg mass collection and larvicide treatment of water containers could be a promising strategy. The aim was to prevent mosquito population outbreak hypothetically associated with the increase of dengue cases from January to May. Results showed that this goal could be achieved depending on the number of eggs destroyed. It is worth pointing out that, as C-OVT were treated with Bti and kept in the same place for 2-month cycles, a large number of larvae originating from eggs laid in the paddles have also been killed. At site 3, where more than $4,000 \mathrm{C}-\mathrm{OVT} / \mathrm{km}^{2}$ were placed, the population growth observed in other sites between January-April 2005 did not 
occur, indicating that vector population boosts can be prevented through this control strategy.

Some aspects relating to the feasibility of incorporating these surveillance and control strategies in large-scale programs, such as automatic estimation of the number of eggs in paddles, and operational costs are being taken into consideration and will be published elsewhere. An egg counting computer-assisted system developed by AFR Araújo and collaborators from the Informatic Center, Federal University of Pernambuco will be soon available. The automatic incorporation of these data into a geographic information system allows producing risk surface maps, using spatial statistics methods available in the open source public domain software Terraview, as an important tool for epidemiological and entomological surveillance activities

There can be no doubt that mass adult collection as a complement to the use of larvicides could produce a faster impact on Ae. aegypti populations, provided an adult trap as efficient, simple and economical as this modified ovitrap is available. In recent years, traps for adult collection have been developed and evaluated under field conditions showing good potential for monitoring Aedes populations (Maciel-de-Freitas et al. 2006, Williams et al. 2006, Facchinelli et al. 2007, Gama et al. 2007).

Finally, it is important to draw attention to the strategy of calling for a network of multi-institutional and multidisciplinary components with integrated use of spatially aware information technology in pursuit of a common goal. This strategy was designed to help increase the competence of the control of transmissible diseases, by providing new tools for surveillance and control systems, including environmental aspects, risk factor detection, and automatic warning methods. It should provide more efficient outbreak detection.

\section{ACKNOWLEDGEMENTS}

To the fieldwork and laboratory staffs from the Secretaria de Saúde do Recife/CVA and CPqAM/Fiocruz. To the people of the Engenho do Meio, Brasilia Teimosa, Morro da Conceição, Alto José do Pinho, Sítio dos Pintos, Dois Irmãos, Casa Forte and Parnamirim districts for their collaboration.

\section{REFERENCES}

Ai-leen TG, Song RJ 2000. The use of GIS in ovitrap monitoring for dengue control in Singapore. Dengue Bull 24: 110-116.

Araújo AP, Melo-Santos MAV, Carlos SO, Rios EMM, Regis L 2007. Evaluation of an experimental product based on Bacillus thuringiensis sorovar. israelensis against Aedes aegypti larvae (Diptera: Culicidae). Biol Control 41: 339-347.

Bailey TC, Gatrell AC 1995. Interactive Spatial Data Analysis, Prentice Hall, Harlow, England, 414 pp.

Barker CM, Paulson SL, Cantrell S, Davis BS 2003. Habitat preference and phenology of Ochlerotatus triseriatus and Aedes albopictus (Diptera: Culicidae) in Southwestern Virginia. J Med Entomol 40: 403-410.

Bellini R, Carrieri M, Burgio G, Bacchi M 1996. Efficacy of different ovitraps and binomial sampling in Aedes albopictus surveillance activity. J Am Mosq Control Assoc 12: 632-636.

Benjamin S, Rath A, Chiang YF, Lee HL 2005. Efficacy of a Bacillus thuringiensis israelensis tablet formulation, VectoBac $\mathrm{DT}^{\circledR}$, for control of dengue vectors in potable water containers. Southeast Asian J Trop Med Public Health 36: 879-892.

Black WC, Moore CG 1996. Population biology as a tool for studying vector-born disease. In BJ Beaty, WC Marquardt, The Biology of Disease Vectors, University Press of Colorado, USA, p. 393-416.

Braga IA, Gomes AC, Nelson M, Mello RCG, Bergamaschi DP, Souza JMP 2000. Comparação entre pesquisa larvária e armadilha de oviposição para detecção de Aedes aegypti. Rev Soc Bras Med Trop 33: 347-353.

Clements AN 1992. The Biology of Mosquitoes, Vol. I, Chapman and Hall, London, $536 \mathrm{pp}$.

Facchinelli L, Valerio L, Pombi M, Reiter P, Constantini C, Della Torre A 2007. Development of a novel sticky trap for containerbreeding mosquitoes and evaluation of its sampling properties to monitor urban populations of Aedes albopictus. Med Vet Entomol 21: 183-195.

Fay RW, Eliason DA 1966. A preferred oviposition site as surveillance method for Aedes aegypti. Mosq News 26: 531-535.

Gama RA, Silva EM, Silva IM, Resende MC, Eiras AE 2007. Evaluation of the sticky MosquiTRAP ${ }^{\mathrm{TM}}$ for detecting Aedes (Stegomyia) aegypti (L.) (Diptera: Culicidae) during the dry season in Belo Horizonte, Minas Gerais, Brazil. Neotrop Entomol 36: 294-302.

Hales S, Panhius W 2005. A new strategy for dengue control. Lancet 365: $551-552$.

Harrington LC, Scott TS, Lerdthusnee K, Coleman RC, Costero A, Clark GG, Jones JJ, Kitthawee S, Kittayapong P, Sithiprasasna R, Edman J 2005. Dispersal of the dengue vector Aedes aegypti within and between rural communities. Am J Trop Med Hyg 72: 209-220.

Hoeck PAE, Ramberg FB, Merrill SA, Moll C, Hagedorn HH 2003. Population and parity levels of Aedes aegypti collected in Tucson. J Vector Ecol 28: 1-9.

Kay B, Nam VS 2005. New strategy against Aedes aegypti in Vietnam. Lancet 365: 613-617.

Lenhart AE, Walle M, Cedillo H, Kroeger A 2005. Building a better ovitrap for detecting Aedes aegypti oviposition. Acta Trop 96: 56-59.

Maciel-de-Freitas R, Eiras AE, Lourenço-de-Oliveira R 2006. Field evaluation of the BG-sentinel, a new trap for capturing adult Aedes aegypti (Diptera: Culicidae). Mem Inst Oswaldo Cruz 101: 321-325.

Maciel-de-Freitas R, Marques WA, Peres RC, Cunha SP, Lourençode-Oliveira R 2007. Variation in Aedes aegypti (Díptera: Culicidae) container productivity in a slum and a suburban district of Rio de Janeiro during dry and wet seasons. Mem Inst Oswaldo Cruz 102: 489-496.

Monteiro AMV, Carvalho MS, Assunção R, Souza WV, Ribeiro Jr PJ, Davis Jr C, Regis L, the SAUDAVEL Project Team 2005. SAUDAVEL: Bridging the Gap between Research and Services in Public Health Operational Programs by Multi-Institutional Networking Development and Use of Spatial Information Tech nology Innovative Tools. [cited 2008 Jan 10]. Available from: http:// www.dpi.inpe.br/saudavel/publicacoes.html.

Morato VCG, Teixeira MG, Gomes AC, Bergamaschi DP, Barreto M 2005. Infestation of Aedes aegypti estimated by oviposition traps in Brazil. Rev Saude Publica 39: 553-558.

Mulla MS, Thavara U, Tawatsin A, Chompoorsi J 2004. Procedures for the evaluation of field efficacy of slow-release formulations of larvicides against Aedes aegypti in water-storage containers. $J$ Am Mosq Control Assoc 20: 64-73.

Nasci RS, Moore CG, Biggerstaff BJ, Pannela NA, Liu HQ, Karabat- 
sos N, Davis BS, Brannon ES 2000. La Crosse encephalitis virus habitat association in Nicholas County, West Virginia. J Med Entomol 37: 559-570.

Polson KA, Curtis C, Seng CM, Olson JG, Chantha N, Rawlins SC 2002. The use of ovitraps baited with hay infusion as a surveillance tool for Aedes aegypti mosquitoes in Cambodia. Dengue Bull 26: 178-184.

Regis L, Oliveira CMF, Silva-Filha MH, Silva SB, Maciel A, Furtado AF 2000. Efficacy of Bacillus sphaericus in control of the filariasis vector Culex quinquefasciatus in an urban area of Olinda, Brazil. Trans R Soc Trop Med Hyg 94: 488-492.

Regis L, Silva-Filha MH, Nielsen-LeRoux C, Charles JF 2001. Bacteriological larvicides of dipteran disease vectors. Trends Parasitol 17: 377-380.

Reiter P, Amador MA, Colon N 1991. Enhancement of the CDC ovitrap with hay infusions for daily monitoring of Aedes aegypti populations. J Am Mosq Control Assoc 7: 52-55.

Ríos-Velasquez CM, Codeço CT, Honório NA, Sabrosa PS, Moresco M, Cunha ICL, Levino A, Toledo LM, Luz SLB 2007. Distributions of dengue vectors in neibghborhoods with different urbanization types of Manaus, state of Amazonas, Brazil. Mem Inst Oswaldo Cruz 102: 617-623.

Ritchie SA, Long S, Hart A, Webb CE, Russell RC 2003. An adulticidal sticky ovitrap for sampling container-breeding mosquitoes. J Am Mosq Control Assoc 19: 235-242.

Sant'Ana AL, Roque RA, Eiras AE 2006. Characteristics of grass infusion as oviposition attractants to Aedes (Stegomyia) (Diptera: Culicidae). J Med Entomol 43: 214-220.

Santos SRA, Melo-Santos MAV, Regis L, Albuquerque CMR 2003. Field evaluation of ovitraps consociated with grass infusion and Bacillus thuringiensis var. israelensis to determine oviposition rates. Dengue Bull 27: 156-162.

Schofield C 1991. Vector population responses to control intervention. Ann Soc Belg Med Trop 71: 201-217.

Scott TW, Amerasinghe PH, Morrison AC, Lorenz LH, Clarck GC, Strickman D, Kittayapong P, Edman JD 2000. Longitudinal stud- ies of Aedes aegypti (Diptera: Culicidae) in Thailand and Puerto Rico: blood feeding frequency. J Med Entomol 37: 89-101.

Setha T, Chantha N, Socheat D 2007. Efficacy of Bacillus thuringiensis israelensis, Vectobac ${ }^{\circledR} \mathrm{WG}$ and DT formulations against dengue mosquito vectors in cement potable water jars in Cambodia. Southeast Asian J Trop Med Public Health 38: 261-268.

Spiegel J, Yassi A, Tate R 2002. Dengue in Cuba: mobilization against Aedes aegypti. Lancet Infect Dis 2: 207-208.

Stoops CA 2005. Influence of Bacillus thuringiensis var. israelensis on oviposition of Aedes albopictus (Skuse). J Vector Ecol 30: 41-44.

Swanson J, Lancaster M, Anderson J, Crandell M, Hamaris L, Grimstad P, Kitron U 2000. Overwintering and establishment of Aedes albopictus (Diptera: Culicidae) in an urban La Cross virus enzootic site in Illinois. $J$ Med Entomol 37: 454-460.

Teixeira MG, Barreto ML, Costa MCN, Ferreira LDA, Vasconcelos PFC 2002a. Avaliação de impacto de ações de combate ao $A e$ des aegypti na cidade de Salvador, Bahia. Rev Bras Epidemiol 5: 108-115.

Teixeira MG, Barreto ML, Costa MCN, Ferreira LDA, Vasconcelos PFC, Cairncross S 2002b. Dynamics of dengue virus circulation: a silent epidemics in a complex urban area. Trop Med Int Health 7: 757-762.

Teixeira MG, Costa MCN, Barreto ML, Mota E 2005. Dengue and dengue hemorrhagic fever epidemics in Brazil: what research is needed based on trends, surveillance and control experiences? Cad Saude Publica 21: 1307-1315.

Toledo-Romani ME, Baly-Gil A, Ceballus-Ursula E, Boelaert M, Stuyft PV 2006. Participación comunitaria en la prevención del dengue: un abordaje desde la perspectiva de los diferentes actores sociales. Salud Publica Mex 48: 39-44.

WHO- World Health Organization 1995. Guidelines for Dengue surveillance and mosquito control. Western Pacific Edu Actions 8, 104 pp.

Williams CR, Long SA, Russell RC, Ritchie SA 2006. Field efficacy of the BG-sentinel compared with CDC backpack aspirators and $\mathrm{CO}_{2}$-baited traps for collection of adult Aedes aegypti in Cairns, Queensland, Australia. J Am Mosq Control Assoc 22: 296-300. 